\title{
Relevant Classes of Weakly Picard Operators
}

Ioan A. Rus

\begin{abstract}
In this paper we consider the following problems:
(1) Which weakly Picard operators satisfy a retractiondisplacement condition? (2) For which weakly Picard operators the fixed point problem is well posed? (3) Which weakly Picard operators have Ostrowski property?

Some applications and open problems are also presented.
\end{abstract}

AMS Subject Classification (2000). 47H10, 54H25, 65J15, $34 \mathrm{Kxx}, 45 \mathrm{Gxx}, 45 \mathrm{~N} 05$

Keywords. metric space, generalized metric space, graphic contraction, Berinde operator, Caristi operator, quasicontraction, weakly Picard operator, retraction-displacement condition, well posedness of the fixed point problem, Ostrowski property, data dependence, Ulam stability, iterative algorithm, functional differential equation, functional integral equation, open problem.

\section{$0 \quad$ Introduction and preliminaries}

Let $(X, \rightarrow)$ be an $L$-space and $f: X \rightarrow X$ be an operator. By definition, $f$ is a weakly Picard operator (WPO) if the sequence $\left\{f^{n}(x)\right\}_{n \in \mathbb{N}}$ converges for all $x \in X$ and its limit (which may depend on $x$ ) is a fixed point of $f$.

If $f$ is a $W P O$, then we consider the operator $f^{\infty}: X \rightarrow X$, defined by, $f^{\infty}(x):=\lim _{n \rightarrow \infty} f^{n}(x)$. We remark that the operator $f^{\infty}$ is a set retraction of $X$ on the fixed point set of $f, F_{f}$. 
Each WPO generates a partition of $X$ in the following way. Let $x^{*} \in F_{f}$ and $X_{x^{*}}:=\left\{x \in X \mid \lim _{n \rightarrow \infty} f^{n}(x)=x^{*}\right\}$. Then, $X=\bigcup_{x^{*} \in F_{f}} X_{x^{*}}$ is a partition of $X$. Moreover, $f\left(X_{x^{*}}\right) \subset X_{x^{*}}$, and $X_{x^{*}} \cap F_{f}=\left\{x^{*}\right\}$.

If $f$ is a $W P O$ and $F_{f}=\left\{x^{*}\right\}$, then by definition, $f$ is called Picard operator $(P O)$.

If $(X, d)$ is a metric space, $f: X \rightarrow X$ is a $W P O$ and $\psi: \mathbb{R}_{+} \rightarrow \mathbb{R}_{+}$ is a function, then by definition $f$ is a $\psi$-WPO iff,

(a) $\psi$ is increasing, continuous at 0 and $\psi(0)=0$;

(b) $d\left(x, f^{\infty}(x)\right) \leq \psi(d(x, f(x))), \forall x \in X$.

We call the condition (b) a retraction-displacement condition.

Remark 0.1. The condition (b) can be presented (in terms of the partition, $\left.X=\bigcup_{x^{*} \in F_{f}} X_{x^{*}}\right)$ as follows

(b) $d\left(x, x^{*}\right) \leq \psi(d(x, f(x))), \forall x \in X_{x^{*}}, \forall x^{*} \in F_{f}$.

The following notion is useful in our paper.

Definition 0.1. Let $(X, d)$ be a metric space, $f: X \rightarrow X$ be a WPO and $0 \leq l<1$. By definition, $f$ is an l-quasicontraction iff

$$
d\left(f(x), f^{\infty}(x)\right) \leq l d\left(x, f^{\infty}(x)\right), \forall x \in X .
$$

In the terms of the partition, $X=\bigcup_{x^{*} \in F_{f}} X_{x^{*}}$, the above condition takes the following form,

$$
d\left(f(x), x^{*}\right) \leq l d\left(x, x^{*}\right), \forall x \in X_{x^{*}}, \forall x^{*} \in F_{f} .
$$

Remark 0.2. There are some relevant metric conditions which appear in the WPO theory. Here are some of them:

(1) $d\left(f^{2}(x), f(x)\right) \leq l d(x, f(x)), \forall x \in X$, with some $0 \leq l<1$.

(2) $d(f(x), f(y)) \leq l d(x, y)+L d(y, f(x)), \forall x, y \in X$, where $0 \leq l<1$, $L \geq 0$.

(3) $\min \{d(f(x), f(y)), d(x, f(x)), d(y, f(y))\}-\min \{d(x, f(y)), d(y, f(x))\}$ $\leq l d(x, y)$, for all $x, y \in X$, with some $0 \leq l<1$. 
(4) There exists a function $\varphi: X \rightarrow \mathbb{R}_{+}$such that, $d(x, f(x)) \leq \varphi(x)-$ $\varphi(f(x)), \forall x \in X$.

Remark 0.3. For more considerations on $P O$ and $W P O$ see: [38], [46], [3], [9], [13], [33], [35], [37], [39], [44], [45], [47], [48], ..

In the paper [44] we have considered the following problems:

Problem 0.1. Which Picard operators satisfy a retraction-displacement condition?

Problem 0.2. For which Picard operators the fixed point problem is well posed?

Problem 0.3. Which Picard operators have the Ostrowski property?

In this paper we shall consider these problems in the case of weakly Picard operators. The structure of the paper is the following:

1. Main results

2. Graphic contractions

3. Berinde operators

4. Caristi operators

5. Applications

6. Other research directions

Throughout this paper the notations and terminologies in [44], [48] and [33] are used.

\section{Main results}

The following results are fundamental to study the problems stated in $\S 0$.

Theorem 1.1. Let $(X, d)$ be a metric space and $f: X \rightarrow X$ be an operator. We suppose that:

(a) $f$ is a WPO

(b) There exists $c>1$ such that:

$$
W_{d, f}(x):=\sum_{n \in \mathbb{N}} d\left(f^{n}(x), f^{n+1}(x)\right) \leq c d(x, f(x)), \forall x \in X
$$

Then we have: 
(1) $d\left(x, f^{\infty}(x)\right) \leq c d(x, f(x)), \forall x \in X$, i.e., $f$ is a $c$-WPO.

(2) $x^{*} \in F_{f}, y_{n} \in X_{x^{*}}, d\left(y_{n}, f\left(y_{n}\right)\right) \rightarrow 0 \Rightarrow y_{n} \rightarrow x^{*}$, i.e., the fixed point problem for $f$ is well posed.

If in addition, $1<c<\frac{3}{2}$, then we have:

(3) $d\left(f(x), f^{\infty}(x)\right) \leq \frac{c-1}{2-c} d\left(x, f^{\infty}(x)\right), \forall x \in X$, i.e., $f$ is a quasicontraction.

(4) $x^{*} \in F_{f}, y_{n} \in X_{x^{*}}, d\left(y_{n+1}, f\left(y_{n}\right)\right) \rightarrow 0 \Rightarrow y_{n} \rightarrow x^{*}$, i.e., $f$ has the Ostrowski property.

(5) Let $Y \subset X$ be a bounded subset with, $f(Y) \subset Y$ and $F_{f} \subset Y$. Then,

$$
\bigcap_{n \in \mathbb{N}} f^{n}(Y)=F_{f}
$$

Proof. (1). $d\left(x, f^{\infty}(x)\right) \leq \sum_{k=0}^{n} d\left(f^{k}(x), f^{k+1}(x)\right)+d\left(f^{n+1}(x), f^{\infty}(x)\right), \forall x \in$ $X, \forall n \in \mathbb{N}$. For $n \rightarrow \infty$ we have that

$$
d\left(x, f^{\infty}(x)\right) \leq W_{d, f}(x), \forall x \in X .
$$

From the condition $(b)$ we have (1).

(2). It follows from (1).

$$
\begin{aligned}
d\left(f(x), f^{\infty}(x)\right) & \leq W_{d, f}(f(x))=W_{d, f}(x)-d(x, f(x)) \leq(c-1) d(x, f(x)) \leq \\
& \leq(c-1) d\left(x, f^{\infty}(x)\right)+(c-1) d\left(f(x), f^{\infty}(x)\right) .
\end{aligned}
$$

So, $d\left(f(x), f^{\infty}(x)\right) \leq \frac{c-1}{2-c} d\left(x, f^{\infty}(x)\right), \forall x \in X$.

(4).

$$
\begin{aligned}
d\left(y_{n+1}, x^{*}\right) \leq & d\left(y_{n+1}, f\left(y_{n}\right)\right)+d\left(f\left(y_{n}\right), x^{*}\right) \leq \\
\leq & d\left(y_{n+1}, f\left(y_{n}\right)\right)+\frac{c-1}{2-c} d\left(y_{n}, x^{*}\right) \leq \\
\leq & d\left(y_{n+1}, f\left(y_{n}\right)\right)+\frac{c-1}{2-c} d\left(y_{n}, f\left(y_{n-1}\right)+\right. \\
& \quad+\ldots+\left(\frac{c-1}{2-c}\right)^{n} d\left(y_{0}, f\left(y_{0}\right)\right)+\left(\frac{c-1}{2-c}\right)^{n} d\left(y_{0}, x^{*}\right) .
\end{aligned}
$$

Now, the proof follows from a Cauchy (or a Toeplitz) lemma. 
(5). Since $f$ is a $W P O$ we have, $X=\bigcup_{x^{*} \in F_{f}} X_{x^{*}}$. Let $y \in X_{x^{*}}$. From (3) we have

$$
d\left(f(y), x^{*}\right) \leq \frac{c-1}{2-c} d\left(y, x^{*}\right) .
$$

From this inequality we have that

$$
\delta\left(f^{n}\left(Y \cap X_{x^{*}}\right),\left\{x^{*}\right\}\right) \leq\left(\frac{c-1}{2-c}\right)^{n} \delta\left(Y \cap X_{x^{*}},\left\{x^{*}\right\}\right) \rightarrow 0 \text { as } n \rightarrow \infty .
$$

So, $\bigcap_{n \in \mathbb{N}} f^{n}\left(Y \cap X_{x^{*}}\right)=\left\{x^{*}\right\}$, and $\bigcap_{n \in \mathbb{N}} f^{n}(Y)=F_{f}$.

Theorem 1.2. Let $X$ be a nonempty set, $d$ and $\rho$ be two metrics on $X$ and $f: X \rightarrow X$ be an operator. We suppose that:

(a) $f:(X, \rho) \rightarrow(X, \rho)$ is WPO.

(b) There exists $c>1$ such that

$$
\sum_{n \in \mathbb{N}} \rho\left(f^{n}(x), f^{n+1}(x)\right) \leq c \rho(x, f(x)), \forall x \in X .
$$

(c) There exists $c_{1}, c_{2}>0$ such that

$$
c_{1} d(x, y) \leq \rho(x, y) \leq c_{2} d(x, y), \forall x, y \in X
$$

Then we have:

(1) $d\left(x, f^{\infty}(x)\right) \leq \frac{c_{2}}{c_{1}} c d(x, f(x)), \forall x \in X$.

(2) The fixed point problem for $f$ is well posed in $(X, d)$.

If in addition $1<c<\frac{3}{2}$, then we have:

(4) $f$ has the Ostrowski property in $(X, d)$.

(5) Let $Y \subset X$ be a bounded subset in $(X, d)$, with $f(Y) \subset Y$ and $F_{f} \subset Y$. Then,

$$
\bigcap_{n \in \mathbb{N}} f^{n}(Y)=F_{f}
$$

Proof. From $(c)$ we have that $f:(X, d) \rightarrow(X, d)$ is a WPO with (1).

$(2),(4)$ and (5) follow from the invariance of these properties with respect to a strongly equivalent metric (see [33]). 


\section{Graphic contractions}

One relevant class of $W P O$ is that of orbitally continuous graphic contractions (see [24], [38], [46], [3], [16], [19], [37], [39], ...). Let $(X, d)$ be a metric space, $f: X \rightarrow X$ be an operator and $0 \leq l<1$. Then by definition $f$ is a graphic l-contraction iff,

$$
d\left(f^{2}(x), f(x)\right) \leq l d(x, f(x)), \forall x \in X .
$$

For this class of operators we have,

Theorem 2.1 (Saturated principle of graphic contraction). Let $(X, d)$ be a complete metric space and $f: X \rightarrow X$ be a graphic l-contraction. Then we have:

(i) $\left\{f^{n}(x)\right\}_{n \in \mathbb{N}}$ converges, $\forall x \in X$ and $\sum_{n \in \mathbb{N}} d\left(f^{n}(x), f^{n+1}(x)\right)<+\infty$, $\forall x \in X$.

If in addition, $\lim _{n \rightarrow \infty} f\left(f^{n}(x)\right)=f\left(\lim _{n \rightarrow \infty} f^{n}(x)\right), \forall x \in X$, then,

(ii) $F_{f}=F_{f^{n}} \neq \emptyset, \forall n \in \mathbb{N}$.

(iii) $f$ is a WPO.

(iv) $d\left(x, f^{\infty}(x)\right) \leq \frac{1}{1-l} d(x, f(x)), \forall x \in X$.

$(v)$ The fixed point problem for $f$ is well posed.

(vi) If $l<\frac{1}{3}$, then

$$
d\left(f(x), f^{\infty}(x)\right) \leq \frac{l}{1-2 l} d\left(x, f^{\infty}(x)\right), \forall x \in X .
$$

(vii) If $l<\frac{1}{3}$, then the operator $f$ has the Ostrowski property.

(viii) Let $l<\frac{1}{3}$. If $Y \in P_{b}(X), f(Y) \subset Y$ and $F_{f} \subset Y$, then,

$$
\bigcap_{n \in \mathbb{N}} f^{n}(Y)=F_{f}
$$

Proof. (i). $\sum_{n \in \mathbb{N}} d\left(f^{n}(x), f^{n+1}(x)\right) \leq\left(\sum_{n \in \mathbb{N}} l^{n}\right) d(x, f(x))=\frac{1}{1-l} d(x, f(x))$.

(ii)-(iii). This is the graphic contraction principle.

(iv)-(viii). Follow from Theorem 1.1. 
Remark 2.1. In some variants of graphic contraction principle the operator $f$ is continuous, or with closed graph, or orbitally continuous.

Remark 2.2. In Turinici [51], an operator $f:(X, d) \rightarrow(X, d)$ is called Picard operator if the sequence $\left\{f^{n}(x)\right\}$ is convergent, for all $x \in X$.

Remark 2.3. In Osilike [25], an operator $f:(X, d) \rightarrow(X, d)$ which satisfies the condition,

$$
\left.\sum_{n \in \mathbb{N}} d\left(f^{n}(x), f^{n+1}(x)\right)\right)<+\infty, \forall x \in X
$$

is called a good operator. In our paper we call such an operator, Weierstrass operator and we use the notation,

$$
W_{d, f}(x):=\sum_{n \in \mathbb{N}} d\left(f^{n}(x), f^{n+1}(x)\right)
$$

From Theorem 2.1 and Theorem 1.1, we have:

Theorem 2.2 (Saturated principle of quasicontraction). Let $(X, d)$ be a metric space and $f: X \rightarrow X$ be an operator such that:

(1) $f$ is WPO.

(2) $f$ is an l-quasicontraction.

Then we have:

(iv) $d\left(x, f^{\infty}(x)\right) \leq \frac{1}{1-l} d(x, f(x)), \forall x \in X$.

(v) The fixed point problem for $f$ is well posed.

(vii) If $l<\frac{1}{3}$, then the operator $f$ has the Ostrowski property.

(viii) Let $l<\frac{1}{3}$. If $Y \in P_{b}(X), f(Y) \subset Y$ and $F_{f} \subset Y$, then,

$$
\bigcap_{n \in \mathbb{N}} f^{n}(Y)=F_{f}
$$

From the Theorem 1.2 and Theorem 2.1, we have:

Theorem 2.3. Let $X$ be a nonempty set, $d$ and $\rho$ be two metrics on $X$. We suppose that:

(1) $f$ is a graphic l-contraction with respect to the metric $\rho$. 
(2) $(X, \rho)$ is a complete metric space.

(3) There exists $c_{1}, c_{2}>0$ such that:

$$
c_{1} d(x, y) \leq \rho(x, y) \leq c_{2} d(x, y), \forall x, y \in X .
$$

Then we have:

(i) $f$ is a Weierstrass operator in $(X, d)$.

If in addition, in the metric space $(X, \rho)$ we have

$$
\lim _{n \rightarrow \infty} f\left(f^{n}(x)\right)=f\left(\lim _{n \rightarrow \infty} f^{n}(x)\right), \forall x \in X,
$$

then,

(ii) $F_{f}=F_{f^{n}} \neq \emptyset, \forall n \in \mathbb{N}^{*}$.

(iii) $f^{n}(x) \stackrel{d}{\rightarrow} f^{\infty}(x) \in F_{f}$.

(iv) $d\left(x, f^{\infty}(x)\right) \leq \frac{c_{2}}{c_{1}(1-l)} d(x, f(x)), \forall x \in X$.

(v) In $(X, d)$, the fixed point problem for $f$ is well posed.

(vii) If $l<\frac{1}{3}$, then $f$ has the Ostrowski property in $(X, d)$.

(viii) Let $l<\frac{1}{3}$. If $Y \in P_{b}(X, d), f(Y) \subset Y$ and $F_{f} \subset Y$, then,

$$
\bigcap_{n \in \mathbb{N}} f^{n}(Y)=F_{f}
$$

\section{$3 \quad$ Berinde operators}

In [2], V. Berinde considered the following class of operators.

Let $(X, d)$ be a metric space, $f: X \rightarrow X$ be an operator, $0 \leq l<1$ and $L \geq 0$. The operator $f$ is called $(l, L)$-almost contraction iff,

$$
d(f(x), f(y)) \leq l d(x, y)+L d(y, f(x)), \forall x, y \in X .
$$

In this paper we call such an operator, $(l, L)$-Berinde operator. For more considerations of this class of operators see also: [7], [3], ..

In our paper we need the following properties of a Berinde operator. 
Lemma 3.1. If $f$ is an $(l, L)$-Berinde operator then $f$ is a graphic l-contraction. So, the Picard iterations are convergent and $f$ is a Weierstrass operator.

Lemma 3.2. For a Berinde operator $f$ we have that:

$$
\lim _{n \rightarrow \infty} f\left(f^{n}(x)\right)=f\left(\lim _{n \rightarrow \infty} f^{n}(x)\right) .
$$

From Theorem 2.1 and the above remarks, we have the following results:

Theorem 3.1 (Saturated theorem of Berinde). Let $(X, d)$ be a complete metric space and $f: X \rightarrow X$ be an $(l, L)$-Berinde operator. Then we have:

(i) $f$ is a Weierstrass operator.

(ii) $F_{f}=F_{f^{n}} \neq \emptyset, \forall n \in \mathbb{N}$.

(iii) $f^{n}(x) \rightarrow f^{\infty}(x) \in F_{f}, \forall x \in X$, i.e., $f$ is a WPO.

(iv) $f$ is $a \frac{1}{1-l}-W P O$.

$(v)$ The fixed point problem for $f$ is well posed.

(vi) If $l<\frac{1}{3}$, then $f$ is an $\frac{l}{1-2 l}$-quasicontraction.

(vii) If $l<\frac{1}{3}$, then $f$ has the Ostrowski property.

(viii) Let $l<\frac{1}{3}$. If $Y \in P_{b}(X), f(Y) \subset Y$ and $F_{f} \subset Y$, then,

$$
\bigcap_{n \in \mathbb{N}} f^{n}(Y)=F_{f}
$$

Theorem 3.2 (Saturated theorem of Berinde, with respect to a strongly equivalent metric). Let $X$ be a nonempty set, $d$ and $\rho$ be two metrics on $X$ and $f: X \rightarrow X$ be an operator. We suppose that:

(a) $(X, \rho)$ is a complete metric space.

(b) There exist $c_{1}, c_{2}>0$ such that,

$$
c_{1} d(x, y) \leq \rho(x, y) \leq c_{2} d(x, y), \forall x, y \in X .
$$

(c) $f$ is an $(l, L)$-Berinde operator with respect to the metric $\rho$.

Then we have the conclusions $(i)-(v)$ and (vii)-(viii) in Theorem 3.1, with respect to the metric $d$ and with 
(iv) $f$ is a $\frac{c_{2}}{c_{1}(1-l)}-W P O$ in $(X, d)$.

Proof. From Theorem 2.1 we have the conclusions $(i)$-(viii) in $(X, \rho)$. From the results given in Petruşel-Rus-Şerban [33], we have the proof.

Remark 3.1. From the above considerations the following questions rise:

Problem 3.1. Which metric conditions imply the graphic contraction condition?

Problem 3.2. Which metric conditions which imply the convergence of Picard iteration imply the condition

$$
\lim _{n \rightarrow \infty} f\left(f^{n}(x)\right)=f\left(\lim _{n \rightarrow \infty} f^{n}(x)\right) ?
$$

Example 3.1. In [13], L.B. Ćirić gives the following result (see also [27]).

Theorem 3.3. Let $(X, d)$ be a metric space and $f: X \rightarrow X$ be an orbitally continuous operator. We suppose that:

(1) $(X, d)$ is $f$-orbitally complete, i.e., every Cauchy sequence of the form $\left\{f^{n_{i}}(x)\right\}, x \in X$, converges in $X$.

(2) There exists $0<l<1$ such that:

$$
\begin{aligned}
& \min \{d(f(x), f(y)), d(x, f(x)), d(y, f(y))\}-\min \{d(x, f(y)), d(y, f(x))\} \\
& \leq l d(x, y), \text { for all } x, y \in X .
\end{aligned}
$$

Then, $\left\{f^{n}(x)\right\}$ converges to a fixed point of $f$.

Now, the proof of Ćiric theorem reads as follows.

Ćirić metric condition implies that $f$ is a graphic $l$-contraction. This implies the convergence of the Picard iterations. The orbitally continuity of $f$ implies that the limits are fixed points of $f$. Moreover we have also the conclusions (iv)-(viii) in Theorem 2.1.

\section{Caristi operators}

An operator $f:(X, d) \rightarrow(X, d)$ is a Caristi operator if there exists a functional $\varphi: X \rightarrow \mathbb{R}_{+}$such that,

$$
d(x, f(x)) \leq \varphi(x)-\varphi(f(x)), \forall x \in X .
$$

The following result is well known (see for example, [10]). 
Lemma 4.1. An operator $f:(X, d) \rightarrow(X, d)$ is a Caristi operator iff $f$ is a Weierstrass operator, i.e.,

$$
W_{d, f}(x):=\sum_{n \in \mathbb{N}} d\left(f^{n}(x), f^{n+1}(x)\right)<+\infty, \forall x \in X .
$$

If $f$ is a $\varphi$-Caristi operator, then,

$$
W_{d, f}(x) \leq \varphi(x), \forall x \in X .
$$

From Lemma 4.1 it follows that the graphic contractions, Berinde operators and Ćirić operators are Caristi operators.

For the class of Caristi operators we have:

Theorem 4.1. Let $(X, d)$ be a complete metric space and $f: X \rightarrow X$ be a $\varphi$-Caristi operator. Then we have that:

(i) $\left\{f^{n}(x)\right\}$ is convergent for all $x \in X$ and $f$ is a Weierstrass operator with, $W_{d, f}(x) \leq \varphi(x)$.

If in addition, $\lim _{n \rightarrow \infty} f\left(f^{n}(x)\right)=f\left(\lim _{n \rightarrow \infty} f^{n}(x)\right), \forall x \in X$, then:

(ii) $F_{f}=F_{f^{n}} \neq \emptyset, \forall n \in \mathbb{N}^{*}$.

(iii) $f^{n}(x) \rightarrow f^{\infty}(x) \in F_{f}, \forall x \in X$.

(iv) If $\varphi(x) \leq c d(x, f(x)), \forall x \in X$, for some $c>1$, then $f$ is $\psi$-WPO, with $\psi(t)=c t, t \geq 0$.

(v) If $\varphi(x) \leq c d(x, f(x)), \forall x \in X$, for some $c>1$, then, the fixed point problem for $f$ is well posed.

(vi) If $\varphi(x) \leq c d(x, f(x)), \forall x \in X$, for some $c \in] 1, \frac{3}{2}\left[\right.$ then $f$ is a $\frac{c-1}{2-c}$ quasicontraction.

(vii) If $\varphi$ is as in (vi), then the operator $f$ has the Ostrowski property.

(viii) Let $\varphi$ be as in (vi). If $Y \subset X$ is bounded, $f(Y) \subset Y$ and $F_{f} \subset Y$, then,

$$
\bigcap_{n \in \mathbb{N}} f^{n}(Y)=F_{f}
$$

Proof. Follows from Theorem 1.1.

Remark 4.1. Let $X$ be a nonempty set, $d$ and $\rho$ be two strongly equivalent metrics and $f: X \rightarrow X$ be an operator. Then the following statements are equivalent:

(1) $f$ is a Caristi operator in $(X, d)$.

(2) $f$ is a Caristi operator in $(X, \rho)$. 


\section{Applications}

\subsection{Data dependence of fixed points under operator perturbation}

Let $(X, d)$ be a complete metric space, $f, g: X \rightarrow X$ be two operators. We suppose that $F_{f} \neq \emptyset, F_{g} \neq \emptyset$ and there exists $\eta>0$ such that $d(f(x), g(x)) \leq$ $\eta, \forall x \in X$. The problem is to estimate, $H_{d}\left(F_{f}, F_{g}\right)$, where $H_{d}$ is the functional of Pompeiu-Hausdorff. In terms of WPO theory a result for this problem is the following (see [37], [38], [46], [48], [3], ...).

Theorem 5.1. Let $(X, d)$ be a metric space and $f, g: X \rightarrow X$ be two operators. We suppose that:

(a) $f$ and $g$ are $\varphi$-WPO.

(b) There exists $\eta>0$ such that,

$$
d(f(x), g(x)) \leq \eta, \forall x \in X .
$$

Then, $H_{d}\left(F_{f}, F_{g}\right) \leq \psi(\eta)$.

From this general result we have some results on data dependence in the case of graphic contractions, Berinde operators, Ćiric operators and Caristi operators, for example.

\subsection{Ulam stability of fixed point equations}

Let $f:(X, d) \rightarrow(X, d)$ be an operator. By definition, the fixed point equation

$$
x=f(x)
$$

is Ulam-Hyers stable if there exists a constant $c_{f}>0$ such that: for each $\varepsilon>0$ and each solution $y^{*} \in X$ of the inequation

$$
d(y, f(y)) \leq \varepsilon
$$

there exists a solution $x^{*}$ of the equation (5.1) such that

$$
d\left(y^{*}, x^{*}\right) \leq c_{f} \varepsilon
$$

For this notion of stability we have:

Theorem 5.2. Let $(X, d)$ be a metric space. If $f: X \rightarrow X$ is a $c-W P O$, then the equation (5.1) is Ulam-Hyers stable.

For this result and for other Ulam stabilities such as: generalized Ulam-Hyers stability, Ulam-Hyers-Rassias stability, see [43], [33], [48], ... 


\subsection{Abstract Gronwall lemmas}

One relevant application of WPO is in the abstract Gronwall lemma theory. For example we have:

Lemma 5.1. Let $(X, \leq, \rightarrow)$ be an ordered L-space and $f: X \rightarrow X$ be an operator. We suppose that:

(a) $f$ is a WPO.

(b) $f$ is increasing.

Then we have that:

(1) $x \leq f(x) \Rightarrow x \leq f^{\infty}(x)$.

(2) $x \geq f(x) \Rightarrow x \geq f^{\infty}(x)$.

In terms of the partition of $X, X=\bigcup_{x^{*} \in F_{f}} X_{x^{*}}$, generated by $f$, the conclusions

(1) and (2) take the following form:

(1) $x \in X_{x^{*}}, x \leq f(x) \Rightarrow x \leq x^{*}, x^{*} \in F_{f}$;

(2) $x \in X_{x^{*}}, x \geq f(x) \Rightarrow x \geq x^{*}, x^{*} \in F_{f}$.

For abstract Gronwall lemmas and for concrete Gronwall lemmas in terms of WPO see: [40], [38], [46], [20], [22], [48], ...

\subsection{Differential, integral, functional differential and functional in- tegral equations}

As basic references in this direction we mention the following: [41], [54], [1], [14], [15], [17], [20], [22], [23], [26], [37], [38], [45], [49], [52], [53], ..

\section{Other research directions}

6.1. What does it mean Saturated principle of fiber WPO ?

References: [49], [50], [46], [48], ...

6.2. What does it mean nonself $W P O$ ?

Take as examples: nonself Berinde operators and nonself Caristi operators.

References: [6], [9], [11], [16], [24], .. 
6.3. To extend the results of our paper to the case of multivalued operators. References: [30], [31], [16], [19], [34], ..

6.4. To study similar problems in the case of generalized metric spaces: $d(x, y) \in \mathbb{R}_{+}^{m} ; d(x, y) \in s\left(\mathbb{R}_{+}\right) ; d(x, y) \in \mathbb{K}$, where $\mathbb{K}$ is a cone in an ordered Banach space, ...

References: [4], [15], [18], [35], [36], [46], ...

6.5. To study similar problems with respect to a convergent iterative algorithm.

References: [3], [5], [8], [12], [21], [32], [42], ..

\section{References}

[1] D.D. Bainov and S.G. Hristova, Differential Equations with Maxima, CRC Press, 2011

[2] V. Berinde, Approximating fixed points of weak contractions using the Picard iteration, Nonlinear Anal. Forum, 9, (2004), 43-53

[3] V. Berinde, Iterative Approximation of Fixed Points, Springer, 2007

[4] V. Berinde and M. Choban, Generalized distance and their associate metrics. Impact on fixed point theory, Creative Math. Infor., 22 (1), (2013), 23-32

[5] V. Berinde, Şt. Măruşter, and I.A. Rus, An abstract point of view on iterative approximation of fixed point of nonself operators, J. Nonlinear Convex Anal., 15, (2014), 851-865

[6] V. Berinde, Şt. Măruşter, and I.A. Rus, Some variants of contraction principle for nonself operators, generalizations and applications, (to appear)

[7] V. Berinde and M. Păcurar, Fixed points and continuity of almost contractions, Fixed Point Theory, 9 (1), (2008), 23-34

[8] V. Berinde and M. Păcurar, Iterative approximation of fixed point of singlevalued almost contraction, In: M.R. Alfuraidan and Q.H. Ansari (eds.), Fixed Point Theory and Graph Theory, Elsevier, (2016), 29-97

[9] V. Berinde, A. Petruşel, I.A. Rus, and M.A. Şerban, The retractiondisplacement condition in the theory of fixed point theory equations with a convergent iterative algorithm, In: T.M. Rassias and V. Gupta (eds.), Mathematical Analysis, Approximation Theory and Their Applications, Springer, (2016), 75-106

[10] V. Berinde and I.A. Rus, Caristi-Browder operator theory in distance spaces, In: M.R. Alfuraidan and Q.H. Ansari (eds.), Fixed Point Theory and Graph Theory, Elsevier, (2016), 1-28 
[11] A. Buică, Principii de coincidenţă şi aplicaţii, Presa Univ. Clujeană, Cluj-Napoca, 2001

[12] C.E. Chidume and Şt. Măruşter, Iterative methods for the computation of fixed point of demicontractive mappings, J. Comput. Appl. Math., 234, (2010), 861-882

[13] L.B. Ćirić, On some maps with a nonunique fixed point, Publ. L'Inst. Math., 17, (1974), 52-58

[14] E. Egri, On First and Second Order Iterative Functional Differential Equations and Systems, Ph.D. Dissertation, Babeş-Bolyai Univ., Cluj-Napoca, 2007

[15] A.-D. Filip, Fixed Point Theory in Kasahara Spaces, Casa Cărţii de Ştiinţă, ClujNapoca, 2015

[16] A. Granas and J. Dugundji, Fixed Point Theory, Springer, 2003

[17] V.A. Ilea, Ecuaţii diferențiale de ordinul întâi cu modificarea mixtă a argumentului, Presa Univ. Clujeană, Cluj-Napoca, 2006

[18] W.A. Kirk and N. Shahzad, Fixed Point Theory in Distance Spaces, Springer, 2014

[19] W.A. Kirk and B. Sims (eds.), Handbook of Metric Fixed Point Theory, Kluwer, 2001

[20] N. Lungu, Qualitative Problems in the Theory of Hyperbolic Differential Equations, Digital Data Cluj, Cluj-Napoca, 2006

[21] Şt. Măruşter and I.A. Rus, Kannan contractions and strongly demicontractive mappings, Creative Math. Inform., 24 (2), (2015), 171-180

[22] V. Mureşan, Functional Integral Equations, Mediamira, Cluj-Napoca, 2003

[23] I.M. Olaru, A study of a nonlinear integral equation via weakly Picard operators, Fixed Point Theory, 16 (1), (2015), 163-174

[24] J.M. Ortega and W.C. Rheinboldt, Iterative Solutions of Nonlinear Equations in Several Variables, Acad. Press, New York, 1970

[25] M.O. Osilike, Stable iteration procedures for strong pseudo-contractions and nonlinear operators, J. Math. Anal. Appl., 204, (1996), 677-692

[26] D. Otrocol, Sisteme Lotka-Volterra cu argument intârziat, Presa Univ. Clujeană, Cluj-Napoca, 2007

[27] B.G. Pachpatte, On Ćirić type maps with a nonunique fixed point, Indian J. Pure Appl. Math., 10, (1979), 1039-1043

[28] M. Păcurar, Iterative Methods for Fixed Point Approximation, Risoprint, ClujNapoca, 2009

[29] M. Păcurar and I.A. Rus, Fixed point theory for cyclic $\varphi$-contractions, Nonlinear Anal., 72, (2010), 1181-1187

[30] A. Petruşel, Multivalued weakly Picard operators and applications, Sci. Math. Jpn., 59, (2004), 167-202

[31] A. Petrussel, Some variants of contraction principle for multivalued operators, generalizations and applications, (to appear) 
[32] A. Petruşel and I.A. Rus, An abstract point of view on iterative approximation schemes of fixed point for multivalued operators, J. Nonlinear Sci. Appl., 6, (2013), 97-107

[33] A. Petruşel, I.A. Rus, and M.A. Şerban, The role of equivalent metrics in fixed point theory, Topological Methods in Nonlinear Anal., 41 (1), (2013), 85-112

[34] A. Petruşel, I.A. Rus, and M.A. Şerban, Basic problems of the metric fixed point theorem for a multivalued operator, J. Nonlinear and Convex Anal., 15 (3), (2014), 493-513

[35] R. Precup, The role of the matrices that are convergent to zero in the study of semilinear operator systems, Math. Computer Modeling, 49, (2009), 703-708

[36] P.D. Proinov, A unified theory of cone metric spaces and its applications to the fixed point theory, Fixed Point Theory Appl. 2013; 2013:103

[37] I.A. Rus, Generalized Contractions and Applications, Cluj Univ. Press, Cluj-Napoca, 2001

[38] I.A. Rus, Picard operators and applications, Sci. Math. Jpn., 58, (2003), 191-219

[39] I.A. Rus, The theory of a metrical fixed point theorem: theoretical and applicative relevance, Fixed Point Theory, 9 (2), (2008), 541-559

[40] I.A. Rus, Gronwall lemmas: ten open problems, Sci. Math. Jpn., 70, (2009), 221-228

[41] I.A. Rus, Some nonlinear functional differential and integral equations, via weakly Picard operator theory: a survey, Carpathian J. Math., 26 (2), (2010), 230-258

[42] I.A. Rus, An abstract point of view on iterative approximation of fixed points: impact on the theory of fixed point equations, Fixed Point Theory, 13 (1), (2012), 179-192

[43] I.A. Rus, Results and problems in Ulam stability of operatorial equations and inclussions, In: T.M. Rassias (ed.), Handbook of Functional Equations: Stability Theory, Springer, (2014), 323-352

[44] I.A. Rus, Some variants of contraction principle, generalizations and applications, Studia Univ. Babeş-Bolyai Math. (to appear)

[45] I.A. Rus, A.S. Mureşan, and V Mureşan, Weakly Picard operators on a set with two metrics, Fixed Point Theory, 6 (2), (2005), 323-331

[46] I.A. Rus, A. Petruşel, and G. Petruşel, Fixed Point Theory, Cluj Univ. Press, Cluj-Napoca, 2008

[47] I.A. Rus, A. Petruşel, and M.A. Şerban, Weakly Picard operators: equivalent definitions, applications and open problems, Fixed Point Theory, 7 (1), (2006), 3-22

[48] I.A. Rus and M.A. Şerban, Basic problems of the metric fixed point theory and the relevance of a metric fixed point theorem, Carpathian J. Math., 29 (2), (2013), $239-258$

[49] M.A. Şerban, Teoria punctului fix pentru operatori definiti pe produs cartezian, Presa Univ. Clujeană, Cluj-Napoca, 2002

[50] M.A. Şerban, Fiber contraction principle, generalizations and applications, (to appear) 
[51] M. Turinici, Selected Topics in Metrical Fixed Point Theory, Editura Pin, 2014

[52] J. Wang, J. Deng, and W. Wei, Fractional iterative functional differential equations with impulses, Fixed Point Theory, 17 (1), (2016), 189-200

[53] J. Wang, Y. Zhou, and M. Medved, Picard and weakly Picard operators techniques for nonlinear differential equations in Banach spaces, J. Math. Anal. Appl., 389 (1), (2012), 261-274

[54] D.Y. Zhou, Basic Theory of Fractional Differential Equations, World Sci. Publ. Co, 2014

Ioan A. Rus

Department of Mathematics

Babeş-Bolyai University

Kogălniceanu Street nr. 1

400084 Cluj-Napoca

Romania

E-mail: iarus@math.ubbcluj.ro

Received: 29.09.2016

Accepted: 30.11 .2016 